\title{
Erratum to: Friction-Induced Transformation from Graphite Dispersed in Esterified Bio-Oil to Graphene
}

\author{
Yufu Xu ${ }^{1} \cdot$ Jian Geng ${ }^{1} \cdot$ Xiaojing Zheng $^{2} \cdot$ Karl D. Dearn ${ }^{3} \cdot$ Xianguo Hu$^{1}$
}

Published online: 28 July 2016

(c) Springer Science+Business Media New York 2016

\section{Erratum to: Tribol Lett (2016) 63:18 \\ DOI 10.1007/s11249-016-0708-5}

Unfortunately, the original publication of the article contained omissions in the captions of Figures 3 and 9. The omissions have been corrected with this erratum.

Figures 3 and 9 captions should read as follows:

Fig. 3 UV-Vis spectra of graphite dispersed in EBO before $(A)$ and after sliding under different loads: $B 100 \mathrm{~N}$, $C 150 \mathrm{~N}$ and $D 200 \mathrm{~N}$

Fig. 9 UV-Vis spectra of graphite dispersed in EBO before $(A)$ and after sliding under different sliding speeds: $B 0.1 \mathrm{~m} / \mathrm{s}, C 0.2 \mathrm{~m} / \mathrm{s}$ and $D 0.3 \mathrm{~m} / \mathrm{s}$ (load: $250 \mathrm{~N}$, sliding time: $60 \mathrm{~min}$ )

The online version of the original article can be found under doi:10.1007/s11249-016-0708-5.

Yufu Xu

xuyufu@hfut.edu.cn

1 Institute of Tribology, School of Mechanical Engineering,

Hefei University of Technology, Hefei 230009, China

2 School of Arts and Media, Hefei Normal University,

Hefei 230601, China

3 School of Mechanical Engineering, University of Birmingham, Edgbaston, Birmingham B152TT, UK 